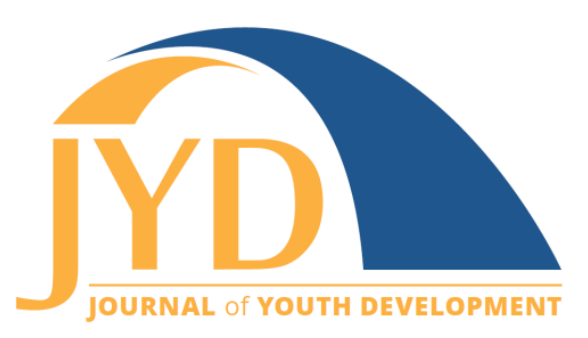

http://jyd. pitt. edu/ | Vol. 14 Issue 4 DOI 10.5195/jyd.2019.809 | ISSN 2325-4017 (online)

\title{
Urban Youth Perspectives on the Benefits and Challenges of Outdoor Adventure Camp
}

\author{
Edmond P. Bowers \\ Clemson University \\ edmondb@clemson.edu
}

Lincoln R. Larson

North Carolina State University

Irlarson@ncsu.edu

Alexandra M. Sandoval

Clemson University

asandov@g.clemson.edu

\begin{abstract}
Consistent evidence indicates that urban youth, and particularly youth of color, report relatively low levels of participation in quality youth program experiences and spend less time outdoors as compared to nonurban and White youth. Outdoor adventure camps (OACS) provide an excellent opportunity for engaging these youth in experiences that can help promote positive youth development (PYD). In the present study, we examined the experiences and perceptions of 75 urban youth who participated in a 3-day high adventure camp experience. Through a mixed-method approach, results indicated that urban youth from all racial and ethnic backgrounds grew in several PYD outcomes including social competencies and selfimprovement capacities. Many youth also reported growing in their connection to nature as a consequence of participating in the OAC. Youth thought camp was a positive and worthwhile experience, reflecting key attributes of a PYD setting. Overall, the OAC provided a challenging and engaging growth environment for youth. Findings highlight implications for socially just and culturally inclusive outdoor adventure programming aimed at diverse urban youth.
\end{abstract}

Key words: adventure programming, positive youth development, nature connection, mixed-methods, urban youth

(cc) $\mathbf{E Y}$ New articles in this journal are licensed under a Creative Commons Attribution 4.0 License. This journal is published by the University Library System, University of Pittsburgh and is cosponsored by the University of Pittsburgh Press. The Journal of Youth Development is the official peer-reviewed publication of the National Association of Extension 4-H Agents and the National AfterSchool Association. 


\section{Urban Youth and Outdoor Adventure Camp}

\section{Introduction}

Engagement in quality youth programs is beneficial for all youth (e.g., Roth \& Brooks-Gunn, 2016). However, participation rates in quality experiences for youth of color, especially those from lower-income urban backgrounds, are relatively low compared to White youth (e.g., Browne Gillard, \& Garst, 2019; Fredericks \& Simpkins, 2012). Youth of color and urban youth also spend less time in the outdoors and report more constraints to nature-based recreation than White youth (Larson, L. R., Green \& Cordell, 2011; Larson, L. R. et al., 2018; Matz, Stieb, $\&$ Brion, 2015). These disparities are exacerbated by a history of White privilege and minority oppression in outdoor settings (Warren, Roberts, Breunig, \& Alvarez, 2014). Such inequities are concerning because they occur during a developmental period when providing opportunities for "expanding horizons, autonomy, challenge, voice, and decision-making" (Saito \& Sullivan, 2011, p. 111) is essential.

Outdoor adventure camps (OACs) can serve as developmental turning points to expose youth to new and diverse people and experiences (Rose-Krasnor \& Ramey, 2018), helping them meet developmental needs and strengthening their connection to nature. These camps exemplify many characteristics of positive youth development (PYD) programs (Sibthorp \& Morgan, 2011), fostering personal growth in outcomes such as empowerment, positive values, and positive identity (Norton \& Watt, 2014; Thurber, Scanlin, Scheuler, \& Henderson, 2007) and creating experiences that promote life skills (e.g., Hattie, Marsh, Neill, \& Richards, 1997). However, not much is known about the conditions that promote positive outcomes in adventure programming (Deane \& Harré, 2014), especially for diverse groups of youth (Browne et al., 2019). There is a need for more information about the impacts of "less structured, but intense activities" (RoseKrasnor \& Ramey, 2018, p. 688). OACs may differentially impact youth of color as well (Green, Kleiber, \& Tarrant, 2000; Warren et al., 2014). Few studies have examined how urban youth of color engage with OACs (Browne et al., 2019; Norton \& Watt, 2014).

In the present study, we examined the experiences and perceptions of racially and ethnically diverse youth from urban communities across eight states who participated in a 3-day high adventure camp experience. We defined "urban youth" using Ellison's (2013) broad definition of "urban," based on "population density, land use practices, or socio-economic-political processes and interactions" (p. 181). The participants in this study came from cities in which populations were greater and denser than the surrounding areas and populations reflected a high degree of diversity of race and class. Through a mixed-methods approach, we aimed to explore ways in 
Urban Youth and Outdoor Adventure Camp

which OAC participation was linked to growth in positive youth competencies and aspects of the experience that were most salient to youth development.

\section{Outdoor Adventure Camps and Positive Youth Development}

OACs provide engaging and risky activities designed to help participants recognize their own weaknesses, strengths, and resources, focusing on competition within the individual and cooperation among group members to achieve goals (Ewert, 1989). These goals foster growth on multiple fronts including self-concept, resiliency, interpersonal skills, leadership, problem solving, and environmental awareness, highlighting potential connections between high-quality OAC experiences and multiple dimensions of PYD (Bowen, Neill, \& Crisp, 2016; Ewert \& Yoshino, 2011; Garst, Browne, \& Bialeschki, 2011; Sibthorp, Paisley, \& Gookin, 2007; Thurber et al., 2007). Meta-analyses have revealed that adolescents who attend adventure programming are $62-65 \%$ better off than their peers on diverse PYD outcomes (Cason \& Gillis, 1994; Hattie et al., 1997).

When examining youth development programming, youth-perceived quality of the setting has a powerful influence on engagement and opportunities for development (Roth \& Brooks-Gunn, 2016). Key characteristics include positive youth-adult relationships, positive peer connections, and engagement in activities (Vandell, 2013). Sibthorp and colleagues (2007) found that outcomes for youth in adventure programming were related to rapport with adult leaders, supportive groups, and individual empowerment. In addition, quality OACs have clear goals, require focus and diligence, provide skill-building opportunities, and challenge youth (Caldwell, 2005). Additionally, OAC activities are often fun and promote youth engagement through youths' own volition, thereby fostering initiative (Larson, R. W., 2000). However, a growing body of research questions whether these outcomes and program elements would apply for youth from culturally diverse backgrounds (Browne et al., 2019).

\section{Urban Youth and Outdoor Adventure Camps}

As OACs have traditionally engaged White youth from higher socioeconomic backgrounds (Browne at al., 2019), few studies have examined the impacts of these experiences on other populations (e.g., urban youth of color). Efforts to engage youth of color in OACs have grown in response to changing demographics in the United States (Gress \& Hall, 2017) with calls to promote access to and positive interactions with nature (White et al., 2016). Through scholarship programs and similar initiatives, racially and socioeconomically diverse youth have 


\section{Urban Youth and Outdoor Adventure Camp}

enhanced access to OACs. However, addressing financial barriers does not eliminate systemic inequalities and power disparities these youth confront at camp (Breunig, 2019; Browne et al., 2019). Despite the rise in opportunities and growth in research regarding marginalized youth and OACs (Caldas, Broaddus, \& Winch, 2016; Gress \& Hall, 2017; Lekies Yost, \& Rode, 2015), limitations persist.

First, studies are rarely comprehensive due to their focus on specific aspects of youth experiences. For example, because enhancing nature-based engagement is a key goal of these efforts, youth experiences of nature (Lekies et al., 2015) or wilderness attitudes (Gress \& Hall, 2017) were often the constructs of interest. Other studies focused on broader outcomes of OACs for youth of color, but did not consider potential processes that impact development (e.g., Caldas et al., 2016; Green et al., 2000). Additionally, most research on wilderness and adventure education outcomes has focused on immersive experiences spanning multiple weeks (e.g., Bowen et al., 2016; Ewert \& Yoshino, 2011). Few studies have examined the impacts of shorter adventure-based camp programming, which may serve as a gateway to longer experiences for youth unfamiliar with the outdoors (Norton \& Watt, 2014; Orren \& Werner, 2007). These short, intense experiences that push youth out of their "comfort zones" can be turning points for both personal growth and connection to nature.

Finally, though non-White and low-income youth are rarely exposed to OACs (Browne et al., 2019), evidence suggests the benefits of these experiences may transcend demographics (Cason \& Gillis, 1994; Hattie et al., 1997; Thurber et al., 2007). Because youth of color display lower participation rates in high-quality youth programs (Fredericks \& Simpkins, 2012) and outdoor recreation in general (Larson, L. R. et al., 2018), short-term OACs might be an ideal step into nature-based programs. However, while efforts to engage marginalized youth through socially-just programming opportunities are important, broader developmental outcomes may be achieved only if these programs are designed to be culturally inclusive (Warren et al., 2014). Transporting urban youth of color into the wilderness may be insufficient; the meaning and benefits youth derive from their experiences depends on how camps foster individual agency, autonomy, and connections to other campers and the camp setting (Breunig, 2019).

\section{The Present Study}

Our study sought to address existing gaps by evaluating the impacts of a short-term OAC experience on diverse urban youth. Our investigation employed quantitative and qualitative methods to address the following questions: 


\section{Urban Youth and Outdoor Adventure Camp}

1. Following the OAC experience, did youth report personal growth and changes in PYD outcomes?

2. What were the most positive aspects of the OAC experience?

3. What aspects of the OAC experience could be improved to maximize positive impacts on participants?

We also explored how outcomes and experiences differed by race/ethnicity when comparisons were possible (e.g., quantitative indicators). While our approach employed somewhat hegemonic methods and interpretations of OAC experiences, two aspects are novel. First, we made a concerted effort to explore the experiences of non-White youth from urban backgrounds, an understudied group. Second, our mixed-methods approach answers calls to capture authentic youth voices in evaluations and explore PYD, a key outcome of interest to OACs.

\section{Method}

\section{Sample}

We evaluated the experiences of urban youth who participated in a 3-day OAC experience at a high adventure camp located in the mountains of West Virginia. One hundred ninety-seven youth participated in the OAC. At home, these youth were participants in career-oriented afterschool programming (58.2\%) or Housing and Urban Development programming (41.8\%) in urban areas (Ellison, 2013) across eight different states. Site leaders from both types of programs were invited to attend the OAC through a message announcing a partnership between the programs sent to site leaders across the country. Site leaders interested in participating in the OAC recruited youth participants. Youth and adult leaders were provided support for their travel and attendance commensurate with need. For many attendees, this was their first camping experience (Scoutingwire, 2016).

OAC activities included canopy tours, climbing walls, shooting sports, mountain biking, and water-based events. As the OAC site provides year-round programming, activities available for youth were already set. Youth, however, had autonomy to choose activities throughout the day. Youth stayed in tents in the same campground. Breakfast and dinner were provided in the site mess hall with portable lunches provided. Each evening ended with a program-wide social event. Although social interactions among different groups of campers-a key element of camp- 
Urban Youth and Outdoor Adventure Camp

based youth development (Jostad, Sibthorp, Pohja, \& Gookin, 2015)—were encouraged, the primary emphasis of the OAC was on experiencing new activities and personal challenges.

Out of 197 youth attendees, the study sample included 75 participants who completed surveys after the 3-day event; $40 \%$ of these surveyed youth were from Housing and Urban Development programming. Youth who completed the surveys ranged in age from 13 to 21 years, and the average age of survey participants was $16.76(S D=2.23)$ with $54.7 \%$ males and $45.3 \%$ females. The survey sample was racially and ethnically diverse: $37.9 \%$ reported being Hispanic or Latino/a, 31.0\% Black or African American, 24.1\% White or Caucasian, 3.4\% multiracial or multiethnic, and $3.4 \%$ another race or ethnicity. ${ }^{1}$ An additional 48 youth participated in small group interviews. In order to explore the perceptions and experiences of diverse participants, the interviewers recruited youth from both types of programming and who reflected the racial and ethnic diversity of the full sample. Twenty-three interviewees identified as male and 25 as female.

\section{Procedures}

Youth gathered together on the last day of camp to complete questionnaires about their camp experiences and camp-mediated changes on diverse PYD outcomes. Questionnaires included quantitative measures and a series of open-ended questions. The research team administered the questionnaires and were available to answer any questions.

Two trained members of the research team also conducted small-group, semi-structured interviews during the second day of the event. Each interview involved two to four participants and averaged 15 to 20 minutes. Youth were recruited to participate in the interviews as they waited to participate in an activity or were engaged in unstructured down time. To address concerns of power differential between interviewer and interviewees, the interviewers dressed in casual clothes that matched the setting. Interviewers also participated in activities and were visible to participants prior to interviews to build comfort with their presence. Interviewers only approached youth who were with other young people. Interviewers also allowed youth to decide if, when, and where they would like participate in an interview. Youth were informed that the interviewers were not employed by the OAC or either of the participating programs,

\footnotetext{
${ }^{1}$ Comparisons of the demographics of the final survey sample to the full set of youth who participated in camp revealed several minor, but non-significant, differences (all $p$ values $>.05$ ), differences. The total set of program youth was composed of Black or African American (38.2\%); Hispanic or Latino/a (33.6\%); 19.8\% Caucasian; $4.6 \%$ multiracial or multiethnic; and 3.8\% another race or ethnicity. The average age of all participants was $16.40(S D=1.96)$ and $60.8 \%$ male.
} 


\section{Urban Youth and Outdoor Adventure Camp}

and that their individual responses would not be shared with anyone. Snacks and drinks were provided during the interviews. To limit reactivity, interviewers emphasized to participants that there were no right or wrong answers, actively listened, and rarely interjected (Seidman, 2013). Interviewers worked to build rapport with youth as a way to reduce response bias (Capella, 1990).

\section{Quantitative Measures}

\section{Youth-Reported Personal Growth.}

On the questionnaire, youth were asked "How much, if any, has your experience as a camper changed your ability to do each of the following things?" Youth reported whether they 1 (decreased), 2 (did not change), 3 (increased a little bit), or 4 (increased a lot) for 16 different outcome variables (See Table 1). Each item was selected based on collaboration between the researchers and program leaders to identify outcomes linked to program leaders' goals for the OAC experience that would also be practical to collect in an OAC setting. Items were based on existing scales such as the Five Cs of PYD (Bowers et al., 2010). While single-item measures can be problematic, prior research has pointed to the reliability and validity of youth-reported, single-item measures ranging from grades (Kuncel, Credé, \& Thomas, 2005) to health (Fosse \& Haas, 2009). In analyses, we incorporated the "decreased" responses into the "did not change" category because only nine responses out of a possible 1200 ( $0.75 \%$ of responses) indicated a decrease.

\section{Youth Perspectives of OAC Quality.}

Youth were also asked their sense of belonging at camp, engagement with camp activities, and relationships with camp staff and peers. Sense of belonging was measured using the five-item Belonging Scale developed by Public/Private Ventures (Gambone \& Arbreton, 1997). A sample item is "I feel like I belonged here." Positive relationships with staff were measured using an adaptation of four items from the Camp Program Quality Assessment (Akiva, 2009). A sample item is "Staff used a warm tone of voice and respectful language here." Positive relationships with peers at camp was measured using Rosenthal and Vandell's (1996) six-item Peer Affiliation scale. A sample item is "I liked the other kids here." Engagement with camp activities was measured using four items from the Program Participation Motivation Scale (Akiva, Cortina, Eccles, \& Smith, 2013). A sample item is "The activities here were important to me." Youth responses on all items ranged from 1 (strongly disagree) to 5 (strongly agree). Cronbach's alphas for the four scales ranged from .90 to .93. 


\section{Urban Youth and Outdoor Adventure Camp}

Analyses of quantitative items included examining overall youth responses and testing whether youth PYD and perceptions of camp quality differed due to youth race/ethnicity through a series of $\mathrm{X}^{2}$ tests and ANOVAs.

\section{Qualitative Measures}

Open-ended questions were also included on the questionnaire so that participants could provide their perceptions of the OAC experience. These items included "What was your favorite part about camp?"; "What was the most challenging part about camp?"; and "What would you change, if anything about camp?"

All small group interviews conducted during day 2 of the camp experience were recorded and then transcribed for analysis. Example questions included "What did you hope to get out of the experience?"; "What are some of the things you learned about yourself at camp?"; "What's something that you will take away from this experience?; and "How did this experience help you feel more connected to nature?

Grounded in a constructivist epistemology (Lincoln, Lynham \& Guba, 2011), conventional content analysis was used to code responses (Hseih \& Shannon, 2005). All members of the research team coded the transcripts and open-ended responses, increasing the rigor of the process (Hruschka et al., 2004). Each coder independently coded (i.e., identified segments of text based on meaning) the data and then coders met to reconcile any discrepancies. The most salient codes within each question were identified based on frequency. The authors then conducted a thematic analysis (Braun \& Clarke, 2012) on the text associated with the most salient codes. Patterns and associations across codes were used to construct overarching themes (Strauss \& Corbin, 1998). Triangulation across multiple coders reduced the potential influence of bias and enhanced the validity of interpretations (Creswell \& Miller, 2000).

\section{Results}

Results are organized to address each question. We integrated quantitative and qualitative findings to provide a more comprehensive understanding of experiences and outcomes. 


\section{RQ1: Following the OAC Experience, Did Youth Report Personal Growth and Changes in PYD Outcomes?}

In general, youth reported multiple forms of personal growth and PYD associated with the camp experience (Table 1). To account for the positive effect that often comes when youth are asked to reflect on recent camping experiences (Gillard, Watts, \& Witt, 2009), we focused on item responses that were significantly different from chance response rates (33\% in each category) and were also supported by convergent evidence derived from qualitative data. Five OAC outcomes met these criteria. Over half of the youth reported "increasing a lot" as a result of their camp experience for four items: "Challenge myself," $\mathrm{X}^{2}(2, n=75)=42.56, p<.001$; "Work together with others," $\mathrm{X}^{2}(2, n=75)=18.96, p<.001$; "Make friends with others," $\mathrm{X}^{2}(2$, $n=75)=17.84, p<.001$; and "Try to be my best," $\chi^{2}(2, n=75)=12.08, p=.002$. These positive changes point to the camp's capacity to nurture positive relationships and to push participants beyond their comfort zones. Many youth also reported substantial increases in their sense of connection to nature, $X^{2}(2, n=75)=8.960, p=.011$. Analyses did not indicate any differences in responses to these five items due to youth race/ethnicity ( $X^{2}$ values ranged from 4.16 to 9.03 , all $p$ values $>.05$ ).

Short-answer responses also highlighted similar areas of personal growth. Trying and experiencing new things (11.7\%) and being challenged and facing fears $(11.7 \%)$ were most frequently identified as youth's favorite part about camp. In many cases, new experiences centered on time in a unique nature setting (e.g., "I'm not around this stuff very often"). In others, new experiences included aspects such as "getting to meet new people and making friends ... we get to learn new things about each other and find out new things about ourselves." 2

Analyses of small group interviews revealed that participants identified learning new skills as the best indication of personal growth during the experience. New skills youth reported learning during the OAC revolved around pushing themselves to try new things. According to one participant, youth "experienced a lot of things [they've] never done" such as being "in the woods, camping, surviving. Learning how to do stuff you don't normally do." The benefits of the experience were acknowledged as a participant noted, "I've never slept in a tent before or anything like that, so this is definitely been a change for me, but I think it's pretty cool." Another youth summarized the experience as "an opportunity you can't turn down because you

\footnotetext{
${ }^{2}$ Full set of youth responses available from the first author upon request.
} 
Urban Youth and Outdoor Adventure Camp

learn a lot. Even if you don't like nature, if you like being inside all day, it really puts you out of your comfort zone. You learn things are not going to hurt you. It's all positives." Youth also saw the benefits of having peers with them to take on these new challenges: "It's really good that we get the opportunity to push each other, and kind of rely on each other. . . . There's a lot of things that individually we didn't want to do. Doing it together has really helped us."

Table 1. Percentage (\%) of Youth Who Reported Personal Growth Linked To ShortTerm Outdoor Adventure Camp Participation $(n=75)$

\begin{tabular}{|l|c|c|c|}
\hline Outcome & $\begin{array}{c}\text { Increased } \\
\text { a lot }\end{array}$ & $\begin{array}{c}\text { Increased } \\
\text { a little bit }\end{array}$ & $\begin{array}{c}\text { Did not } \\
\text { change }\end{array}$ \\
\hline Challenge myself & 68.0 & 22.7 & 9.3 \\
\hline Work together & 56.0 & 28.0 & 25.3 \\
\hline Make friends & 56.0 & 18.7 & 26.7 \\
\hline Try to be my best & 52.0 & 21.3 & 22.7 \\
\hline Feel connected to nature & 49.3 & 28.0 & 28.0 \\
\hline Be happy the way I am & 49.3 & 22.7 & 24.0 \\
\hline Learn from mistakes & 46.7 & 29.3 & 29.3 \\
\hline Do what is right & 46.7 & 24.0 & 25.3 \\
\hline Listen to others & 45.3 & 29.3 & 26.7 \\
\hline Finish what I start & 44.0 & 29.3 & 29.3 \\
\hline Take responsibility & 44.0 & 26.7 & 21.0 \\
\hline Career exploration & 42.7 & 13.3 & 20.0 \\
\hline Be a good leader & 40.0 & 38.7 & 25.3 \\
\hline Solve problems & 38.7 & 41.3 & 29.3 \\
\hline Show self control & 37.3 & 37.3 & 34.7 \\
\hline Make good decisions & 36.0 & & 2.3 \\
\hline
\end{tabular}

Notes. Percentages in table are valid percent of youth who responded to the items. "Did not change" category also includes a few youth responses of "Decreased."

\section{RQ2: What Were the Most Positive Aspects of the OAC Experience?}

Overall, youth felt a sense of belonging $(M=3.84, S D=0.79)$ at the camp and reported positive relationships with their peers $(M=3.59, S D=1.00)$. They also reported particularly favorable responses to their relationships with staff $(M=4.31, S D=0.73)$ and their engagement with the activities $(M=4.33, S D=0.66)$. We conducted repeated measures 


\section{Urban Youth and Outdoor Adventure Camp}

ANOVA to examine whether youth perceived these four program aspects to be of different quality. The repeated measures ANOVA results with a Greenhouse-Geisser correction indicated that there were significant differences in how these program aspects were perceived, $F(1.94$, $139.71)=34.34, p<.001$. Post hoc analyses (paired t-tests with a Bonferroni correction, $\mathrm{a} / 6=$ .008 ) indicated that youth viewed engagement with the activities and relationships with staff significantly higher than they perceived their sense of belonging and relationships with peers ( $t$ ranged from 5.45 to 7.05 , all $p$ values $<.001$ ). Sense of belonging, in turn, was also rated significantly higher than relationships with peers, $t(72)=3.19, p=.002$. Analyses did not indicate any differences in average rating of each dimension due to youth race/ethnicity ( $F$ values ranged from 0.43 to 2.08 , all $p$ values $>.05$ ).

Open-ended responses supported youth ratings of the quality of the OAC experience. That is, almost half of the participants focused on the activities themselves as their favorite part (48.5\%, with zip lining as one of the major highlights). The second most frequently described favorite part of camp was bonding with others (19.4\%), which affirmed the high sense of belonging and relatively positive peer relationships.

In small group interviews, participants identified the activities, spending time outdoors, and meeting new people as the most enjoyable aspects of camp. Youth thought the experience was worthwhile and enjoyable. Activities were recognized as contributing to enjoyment, as one participant indicated: "You get to do a lot, where at home you're not doing much." Another youth said, "It's a ton of fun. At first, it didn't seem like it was going to be worth the 24-hour drive, but it's already worth it." A third offered a lifetime benefit of the experience: "We don't have any of this at home, like activities here. We can take that back and tell other people about it. We can cross some stuff off our bucket list."

Spending time outdoors was also noted by participants as a key aspect to the experience, with many youth recognizing the simplicity of just experiencing nature through reflections such as: "Walking on the trails is like, you might be tired, but it's really nice getting out and seeing everything;" and "It's...like a peaceful place where you can just get out there and get your mind away from everything... and just try to have some fun and not worry about things."

Participants also described the value of novel nature-based experiences. Many youth noted that spending time outdoors greatly contributed to their enjoyment and impacted the way they think about nature. One participant observed the soothing power of nature: "One thing I did like is when you're in your tent and all you hear is nature, it's really calming" and another participant 


\section{Urban Youth and Outdoor Adventure Camp}

pointed to the positive experience of being an outdoor setting: "I liked it because I like nature. I like how fresh it feels. The air, I know it sounds weird, but when you breathe in the air, it's fresh. It's nice. And over there [a large city in Texas], it's not as nice."

Another contributor to youth enjoyment during camp was meeting new people. Youth noted the experience provided opportunities for connecting with others as they enjoyed "Meeting new people, and the sense of like teamwork." including those "from other states, maybe cities around our area." The OAC experience also provided opportunities for getting to know youth from one's own program better. For example, a participant explained, "In our training meetings it's so awkward because none of us really knew each other, because we all came in at different times. ... We came here and all of us bonding, having no problem with it... it's a lot of fun."

\section{RQ3: What Aspects of OAC Experience Could Be Improved to Maximize Potential Impacts on Participants?}

Although enjoyed by most youth, high adventure activities were also the most frequently cited challenge of the experience (noted by $36.1 \%$ of youth). The perils of camping and outdoor living also appeared to weigh on quite a few participants (20.8\%). For example, one participant indicated struggles "getting used to the outdoor showers, bugs in the tent, and mud." Another participant pointed to the challenge of "keeping my phone charged to document my experience!" Almost a fifth of participants (19.4\%) indicated that the amount of walking between activities and stations was difficult. When asked what they would change about the experience, most recommendations reflected these perceived challenges. For example, a number of participants (22.8\%) indicated ways to alter the accommodations to enhance comfort (e.g., cabins, hot showers). Many wanted to see a greater variety of activities, including some better tailored to different skill levels (13.9\%). Other campers (12.7\%) lamented the large distances between activities and advocated for transportation options or reported that food options could be improved (12.7\%).

Analyses of the small group interviews revealed similar challenges. A key theme was that participants viewed getting lost and being unprepared for camping as the most challenging aspects of the experience. For example, a participant indicated, "It's a little hard to find things. We were hoping there would be a little bit more signs, but we also had a little bit of a difficult time reading the maps." Another participant "didn't anticipate how dirty it would be... I never been camping for a week. I came under-prepared." In many cases these issues stemmed from home program staff and OAC site staff not properly preparing youth with limited nature-based 


\section{Urban Youth and Outdoor Adventure Camp}

experiences for the camp setting. A participant expressed how their group was not properly equipped for camping: "... Just not being really prepared as we should have been. For one, we don't have flashlights so we're having to improvise and use our phones and stuff like that. Not bringing water shoes. I had to use my own shoes."

\section{Discussion}

Our multi-method assessment of youth perspectives of an OAC revealed that a majority of diverse urban youth viewed the camp as worthwhile and benefited from the experience in many ways, impacting several PYD outcomes. Benefits were reported by urban youth across all racial/ethnic backgrounds. It is important to consider that youth, particularly youth of color less familiar with outdoor settings (Breunig, 2019), may have responded in a more positive way due to social desirability or due to the positive affect that comes at the end of an intensive experience (Gillard et al., 2009). We therefore focused on youth-reported OAC outcomes that were supported by multiple data sources.

Our findings extend prior research indicating personal growth following OAC participation (Ewert, 1989; Hattie et al., 1997). Youth reported that they grew in social competencies ("Make friends with others" and "Work together with others") and self-improvement capacities ("Challenge myself" and "Try to be my best"). Therefore, the camp benefited two dimensions of skills important for PYD: social skills and internal motivation (Gutman \& Schoon, 2016; Larson, R. W., 2000). We did not observe differences among racial/ethnic groups on these outcomes. These findings are encouraging, and align with previous work suggesting that all youth, regardless of background, can benefit from OAC experiences (Norton \& Watt, 2014). Results indicated that the OAC provided a challenging and engaging opportunity for youth who rarely experience such opportunities (Browne et al., 2019), reflecting key attributes of PYD settings (Larson, R. W., 2000). Key aspects of the experience for youth were bonding with others, challenging themselves, and appreciating the value of trying new things. These findings are consistent with the expected outcomes of short term, intense activities such as OACs (RoseKrasnor \& Ramey, 2018). Youth reported that the experience helped them nurture positive connections with others and pushed them beyond their comfort zones in a positive way. By providing novel challenging opportunities, the camp allowed participants to develop and test new knowledge and skills (Garst et al., 2011).

Although many activities were unfamiliar and challenging, youth reported being highly engaged; in fact, the activities were participants' favorite part of the experience. Positive engagement 


\section{Urban Youth and Outdoor Adventure Camp}

with activities was complemented by youth-reported sense of belonging and positive interactions with the staff and peers. Similar studies of other youth development programs reinforce the importance of a caring adult-youth and peer relationships in a variety of settings (Roth \& Brooks-Gunn, 2016), including outdoor (Ungar, Dumond, \& McDonald, 2005) and adventure programs for youth from disadvantaged backgrounds (Green et al., 2000). However, youth in our study were more likely to emphasize adventure sports and activities as the highlight of camp when compared to social interactions. This result is not surprising, for the OAC program we studied prioritized novel experiences and personal challenges over peer bonding. A stronger focus on social aspects of camp might have yielded even greater benefits for urban youth of color; previous research has shown that African American youth attending wilderness programs value group support and physical and emotional safety more than novel experiences (Orren \& Werner, 2007).

Taken together, youth experiences at camp were consistent with philosophies of PYD settings (e.g., Roth \& Brooks-Gunn, 2016) and quality out-of-school time programs (Vandell, 2013). This experience also reflected the three program elements required to promote initiative in youth (Larson, R. W., 2000): (a) youth reported having fun in the activities; (b) they were challenged to engage more fully in the activities; and (c) although the experience was relatively brief, there was also effort directed toward a goal that was marked by set-backs, contemplation, and selection of different strategies. The camp did not, however, attempt to be intentionally inclusive or culturally relevant to all groups of campers, many of whom were experiencing an OAC for the first time (Browne et al. 2019). While all groups of youth in our study seemed to benefit from the OAC, these changes are something to consider in future programs focused on historically marginalized youth (Breunig, 2019; Warren et al., 2014).

The camp experience appeared to have a positive impact on youths' environmental perceptions and connection to nature, generally conceptualized as their affective enjoyment and sense of oneness with the natural world (Cheng \& Monroe, 2012). After camp, 49\% of youth said their connection to nature had increased a lot, and $28 \%$ said this connection had increased a little bit. Interview responses during camp supported these results, demonstrating tangible changes in the way that youth thought about nature. These findings support the idea that camps provide novel settings for recreation experiences and sustained time in nature (Garst et al., 2011), helping to provide a number of physical, social, and psychological benefits and combat the "extinction of experience" plaguing contemporary youth (Louv, 2005; Soga \& Gaston, 2016). They also support previous studies suggesting links between outdoor education and connection to nature (Braun \& Dierkes, 2017), particularly when camps engage urban youth in natural 


\section{Urban Youth and Outdoor Adventure Camp}

settings (Collado, Staats, \& Corraliza, 2013). Despite positive feedback regarding enhanced nature connections, the benefits of the OAC on environmental awareness and learning were less clear even though informal outdoor education has the capacity to advance these learning goals (Falk, Heimlich, \& Foutz, 2009) and gains in awareness of environmental issues have been reported following outdoor programs for youth from disadvantaged backgrounds (Staples, Larson, Worsley, Green, \& Carroll, 2019; Ungar et al., 2005). Perceptions of positive connections to nature might be offset by the negative youth experiences in the outdoors. These mixed reactions to nature are consistent with prior research involving urban youth (Lekies et al, 2015). This work suggests that environmental awareness outcomes vary significantly depending on the nature and structure of the programs (Sibthorp et al., 2007), such as longer stays and more active engagement with trained staff and instructors (Stern, Powell, \& Ardoin, 2008). Overall, our study suggests that a short-term OAC experience might increase nature-related curiosity and short-term connection to nature, but lasting gains remain uncertain and might require longer periods of nature engagement (Braun \& Dierkes, 2017). Enhanced attention to regular and consistent environmental socialization in closer-to-home, culturally relevant contexts may be necessary to achieve those goals (Kellert et al., 2017).

\section{Limitations}

There were several limitations in this study. Setting aside dedicated time to collect data with all youth at the end of camp was difficult, resulting in relatively low response rates. We elected to survey youth at breakfast prior to departure, but several groups skipped breakfast to travel home. Therefore, responses may not represent the full sample of camp participants. To alleviate this concern, we note that youth from both program types provided data, sample demographics matched the overall OAC participants' demographics, small group interviews included youth from all programs, and camp-related benefits were identified using evidence from multiple sources.

A second limitation is that despite our mixed-methods approach, results were based solely on youth perceptions. Many of these perspectives were captured using single items to assess a diverse set of outcomes. Although there is support for the psychometric soundness of singleitem measures for some outcomes (e.g., Fosse \& Haas, 2009), such items may not fully capture the construct. Additional sources of data such as program leaders, site staff, and observations would enhance robustness of findings and limit respondent bias concerns.

Despite our conservative analytical approach, responses might have also been influenced by "post-group euphoria" when self-reported data are collected soon after the camp experience 


\section{Urban Youth and Outdoor Adventure Camp}

(Gillard et al. 2009). Additionally, it should be noted that this OAC did not incorporate strategic interactions and facilitated reflections that define typical adventure education experiences (Bowen et al., 2016; Ewert, 1989; Hattie et al., 1997), instead offering a less structured but intense experience. With more structure and intentional programming, PYD outcomes might have been greater. For example, programs with emphases beyond just adventure activities that integrate therapeutic group procedures are often effective for youth deemed "at-risk" (Bowen et al., 2016; Green et al., 2000).

Although the study revealed no differences among racially and ethnically diverse youth, the relatively small sample size limited the statistical power to detect small differences. Finally, while this evaluation offered evidence of short-term changes for youth, the long-term outcomes of this OAC have yet to be determined. Follow-up support is key to sustaining gains for youth from disadvantaged backgrounds (Ungar et al., 2005), and may apply to our sample of urban youth with limited outdoor experience (Browne et al., 2019).

\section{Implications for Practice and Future Research}

There were several areas that could be strengthened in future OACs. The most salient challenges associated with the experience involved: (a) the adventure activities, which challenged youth to test their skills and face their fears; (b) the physical activity and endurance required to navigate the campus and access activities; and (c) the challenges of camping outdoors. While many campers complained about these aspects, they also noted the value of each. Consistent with prior research, our results suggest that overnight OACs can also contribute to physical health (Hickerson \& Henderson, 2014) and mental health (Jostad et al., 2015; Rose-Krasnor \& Ramey, 2018).

Many of the urban youth groups were simply not prepared for the experiences and the unique challenges camp presented. The reported lack of preparedness at the group level, which appeared to dampen the overall experience, could be addressed through pre-camp communication, information, and activities to prepare youth and adult participants for this type of adventure. These changes in framing and communication could help address recent calls for camp programs that are both social justice-oriented and culturally inclusive (Warren et al., 2014).

Despite overall positive perceptions of the experience, these positive views may not have been shared by all youth. For example, perceived sense of belonging and relationships with peers 


\section{Urban Youth and Outdoor Adventure Camp}

were rated lower than engagement with activities and relationships with staff. Peer bonding and social interactions may be particularly important for urban youth of color experiencing unfamiliar settings (Orren \& Werner, 2007), and activities and events could be designed to foster these relationships. Future efforts should explore ways OAC experiences can be structured to create inclusive and positive experiences for diverse youth (Warren et al., 2014).

While this study offers some insights about the impacts of OAC on the positive development of diverse urban youth, questions and opportunities remain. Do the self-reported benefits of OAC experiences persist when youth return home? Would integration of more structured and intentional activities facilitating personal reflection, group interaction, and nature connection lead to additional PYD outcomes? Would youth reap greater benefits from participating in a longer outdoor recreation experience? More research is needed to understand the processes that lead to OAC outcomes (Bowen et al., 2016; Hattie et al., 1997) among different populations and across different contexts (Browne et al., 2019). Our findings highlight the capacity of OAC experiences to shape PYD in diverse youth, generating benefits despite systemic barriers to participation in a historically "White" activity (Browne et al., 2019). Youthserving professionals should work with partner organizations to increase access to OAC opportunities for youth from urban, low-income, and racial/ethnic minority backgrounds. A short-duration overnight program may be a realistic and fruitful place to start.

\section{Acknowledgements}

This work was supported by a grant from the Boy Scouts of America National Foundation to Edmond P. Bowers and Lincoln R. Larson.

\section{References}

Akiva. T. (2009). The camp program quality assessment: (Camp PQA): Development and pilot study. Ypsilanti, MI: David P. Weikart Center for Youth Program Quality.

Akiva, T., Cortina, K. S., Eccles, J. S., \& Smith, C. (2013). Youth belonging and cognitive engagement in organized activities: A large-scale field study. Journal of Applied Developmental Psychology, 34(5), 208-218. doi:10.1016/j.appdev.2013.05.001

Bowen, D. J., Neill, J. T., \& Crisp, S. J. R. (2016). Wilderness adventure therapy effects on the mental health of youth participants. Evaluation and Program Planning, 58, 49-59. doi:10.1016/j.evalprogplan.2016.05.005 


\section{Urban Youth and Outdoor Adventure Camp}

Bowers, E. P., Li, Y., Kiely, M. K., Brittian, A., Lerner, J. V., \& Lerner, R. M. (2010). The Five Cs model of positive youth development: A longitudinal analysis of confirmatory factor structure and measurement invariance. Journal of Youth and Adolescence, 39(7), 720-735. doi:10.1007/s10964-010-9530-9

Braun, V., \& Clarke, V. (2012). Thematic analysis. In Cooper, H. (Ed.), Research methods in psychology (pp. 57-71). American Psychological Association, Washington D.C.

Braun, T., \& Dierkes, P. (2017). Connecting students to nature-how intensity of nature experience and student age influence the success of outdoor education programs. Environmental Education Research, 23(7), 937-949.

Breunig, M. (2019). Beings who are becoming: Enhancing social justice literacy. Journal of Experiential Education, 42(1), 7-21. doi:10.1177/1053825918820694

Browne, L. P., Gillard, A., \& Garst, B. A. (2019). Camp as an institution of socialization: Past, present, and future. Journal of Experiential Education, 42(1), 51-64. doi:10.1177/1053825918820369

Caldas, S. V., Broaddus, E. T., \& Winch, P. J. (2016). Measuring conflict management, emotional selfefficacy, and problem solving confidence in an evaluation of outdoor programs for inner-city youth in Baltimore, Maryland. Evaluation and program planning, 57, 64-71. doi:10.1016/j.evalprogplan.2016.04.003

Caldwell, L. (2005). Recreation and youth development. In P. Witt \& L. Caldwell (Eds.), Recreation and youth development (pp. 169-191). State College, PA: Venture.

Capella, J. N. (1990). On defining conversational coordination and rapport. Psychological Inquiry, 1(4), 303-305. doi:10.1207/s15327965pli0104_5

Cason, D., \& Gillis, H. L. (1994). A meta-analysis of outdoor adventure programming with adolescents. Journal of Experiential Education, 17(1), 40-47. doi:10.1177/105382599401700109

Cheng, J. C. H., \& Monroe, M. C. (2012). Connection to nature: Children's affective attitude toward nature. Environment and Behavior, 44(1), 31-49. 10.1177/0013916510385082

Collado, S., Staats, H., \& Corraliza, J. A. (2013). Experiencing nature in children's summer camps: Affective, cognitive and behavioural consequences. Journal of Environmental Psychology, 33, 3744. doi:10.1016/j.jenvp.2012.08.002

Creswell, J. W., \& Miller, D. L. (2000). Determining validity in qualitative inquiry. Theory into Practice, 39(3), 124-130. doi:10.1207/s15430421tip3903_2

Deane, K. L., \& Harré, N. (2014). The youth adventure programming model. Journal of Research on Adolescence, 24(2), 293-308.

Ellison, K. L. (2013). Fostering outdoor learning experiences with urban youth through place-based expeditionary learning. Journal of Outdoor Recreation, Education, and Leadership, 5(3), 179-191. doi:10.7768/1948-5123.1170 


\section{Urban Youth and Outdoor Adventure Camp}

Ewert, A. (1989). Outdoor adventure pursuits: Foundations, models, and theories. Columbus, $\mathrm{OH}$ : Publishing Horizons.

Ewert, A., \& Yoshino, A. (2011). The influence of short-term adventure-based experiences on levels of resilience. Journal of Adventure Education and Outdoor Learning, 11(1), 35-50. doi:10.1080/14729679.2010.532986

Falk, J. H., Heimlich, J. E., \& Foutz, S. (2009). Free choice learning and the environment. Lanham, MD: AltaMira Press.

Fosse, N. E., \& Haas, S. A. (2009). Validity and stability of self-reported health among adolescents in a longitudinal, nationally representative survey. Pediatrics, 123(3): e496-e501. doi:10.1542/peds.2008-1552

Fredricks, J. A., \& Simpkins, S. D. (2012). Promoting positive youth development through organized afterschool activities: Taking a closer look at participation of ethnic minority youth. Child Development Perspectives, 6(3), 280-287. doi:10.1111/j.1750-8606.2011.00206.x

Gambone, M. A., \& Arbreton, A. J. (1997). Safe havens: The contributions of youth organizations to healthy adolescent development. Philadelphia, PA: Public/Private Ventures.

Garst, B. A., Browne, L. A., \& Bialeschki, M. D. (2011). Youth development and the camp experience. New Directions for Youth Development, 130, 73-87. doi:10.1002/yd.398

Gillard, A., Watts, C. E., \& Witt, P. A. (2009). Camp Supports for Motivation and Interest: A MixedMethods Study. Journal of Park \& Recreation Administration, 27(2), 74-96.

Green, G. T., Kleiber, D. A., \& Tarrant, M. A. (2000). The effect of an adventure-based recreation program on development of resiliency in low income minority youth. Journal of Park and Recreation Administration, 18(3), 76-97.

Gress, S., \& Hall, T. (2017). Diversity in the outdoors: National outdoor leadership school students' attitudes about wilderness. Journal of Experiential Education, 40(2), 114-134. doi:10.1177/1053825916689267

Gutman, L. M., \& Schoon, I. (2016). A synthesis of causal evidence linking non-cognitive skills to later outcomes for children and adolescents. In M. S. Khine \& S. Areepattamannil (Eds.), Non-cognitive skills and factors in educational attainment (pp.171-198). Rotterdam, The Netherlands: Sense Publishers.

Hattie, J., Marsh, H. W., Neill, J. T., \& Richards, G. E. (1997). Adventure education and Outward Bound: Out-of-class experiences that make a lasting difference. Review of Educational Research, $6 \pi(1)$, 43-87.

Hickerson, B. D., \& Henderson, K. A. (2014). Opportunities for promoting youth physical activity: An examination of youth summer camps. Journal of Physical Activity and Health, 11, 199-205. doi:10.1123/jpah.2011-0263 
Journal of Youth Development | http://jyd.pitt.edu/ | Vol. 14 Issue 4 DOI 10.5195/jyd.2019.809

\section{Urban Youth and Outdoor Adventure Camp}

Hruschka, D. J., Schwartz, D., St. John, D. C., Picone-Decaro, E., Jenkins, R. A., \& Carey, J. W. (2004). Reliability in coding open-ended data: Lessons learned from HIV behavioral research. Field Methods, 16(3), 307-331. doi:10.1177/1525822X04266540.

Hseih, H. F. \& Shannon, S.E. (2005). Three approaches to qualitative content analysis. Qualitative Health Research, 15(9), 1277-88. doi:10.1177/1049732305276687

Jostad, J., Sibthorp, J., Pohja, M., \& Gookin, J. (2015). The adolescent social group in outdoor adventure education. Research in Outdoor Education, 13(1), 16-37. doi:10.1353/roe.2015.0002

Kellert, S. R., Case, D. J., Escher, D., Witter, D. J., Mikels-Carrasco, J., \& Seng, P. T. (2017). The nature of Americans: Disconnection and recommendation for reconnection. Available from https://natureofamericans.org/

Kuncel, N. R., Credé, M., \& Thomas, L. L. (2005). The validity of self-reported grade point averages, class ranks, and test scores: A meta-analysis and review of the literature. Review of Educational Research, 71), 63-82. doi:10.3102/00346543075001063

Larson, L. R., Green, G. T., \& Cordell, H. K. (2011). Children's time outdoors: Results and implications of the National Kids Survey. Journal of Park and Recreation Administration, 29(2), 1-20.

Larson, L. R., Szczytko, R., Bowers, E. P., Stephens, L. E., Stevenson, K. T., \& Floyd, M. F. (2018). Outdoor time, screen time, and connection to nature: Troubling trends among rural youth? Environment and Behavior. doi:10.1177/0013916518806686

Larson, R. W. (2000). Toward a psychology of positive youth development. American Psychologist, 55(1), pp. 170-183. doi:10.1037//0003-066X,55.1.170

Lekies, K. S., Yost, G., \& Rode, J. (2015). Urban youth's experiences of nature: Implications for outdoor adventure recreation. Journal of Outdoor Recreation and Tourism, 9, 1-10. doi:10.1016/j.jort.2015.03.002

Lincoln, Y. S., Lynham, S. A., \& Guba, E. G. (2011). Paradigmatic controversies, contradictions, and emerging confluences, revisited. The Sage handbook of qualitative research, 4, 97-128.

Louv, R. (2005). Last child in the woods: Saving our children from nature-deficit disorder. Chapel Hill, NC: Algonquin Books of Chapel Hill.

Matz, C. J., Stieb, D. M., \& Brion, O. (2015). Urban-rural differences in daily time-activity patterns, occupational activity and housing characteristics. Environmental Health, 14(1), 88. doi:10.1186/s12940-015-0075-y

Norton, C. L., \& Watt, T. T. (2014). Exploring the impact of a wilderness-based positive youth development program for urban youth. Journal of Experiential Education, 374), 335-350. doi:10.1177/1053825913503113

Orren, P. M., \& Werner, P. D. (2007). Effects of brief wilderness programs in relation to adolescents' race. Journal of Experiential Education, 30(2), 117-133. doi:10.1177/105382590703000203 


\section{Urban Youth and Outdoor Adventure Camp}

Rose-Krasnor, L., \& Ramey, H. L. (2018). Youth activity participation: An ecological peer-based approach for positive youth development. In W. M. Bukowski, B. Lauren, \& K. H. Rubin (Eds.) Handbook of peer interactions, relationships, and groups, $2^{\text {nd }}$ edition (pp. 676 - 695). New York, NY: The Guilford Press.

Rosenthal, R., \& Vandell, D. L. (1996). Quality of care at school-aged child care programs: Regulatable features, observed experiences, child perspectives, and parent perspectives. Child Development, 67, 2434-2445. doi:10.2307/1131632

Roth, J. L., \& Brooks-Gunn, J. (2016). Evaluating youth development programs: Progress and promise. Applied developmental science, 20(3), 188-202. doi:10.1080/10888691.2015.1113879

Saito, R.N., \& Sullivan, T.K. (2011). The many faces, features, and outcomes of youth engagement. Journal of Youth Development, 6(3), 109-125. doi:10.5195/jyd.2011.178

Scoutingwire. (2016, August 3). Exploring Summerfest debuts at the Summit Bechtel Reserve. Retrieved from https://scoutingwire.org/exploring-summerfest-debuts-at-the-summit-bechtel-reserve/

Seidman, I. (2013). Interviewing as qualitative research: A guide for researchers in education and the social sciences ( $4^{\text {th }}$ ed.). New York, NY: Teachers College Press.

Sibthorp, J., \& Morgan, C. (2011). Adventure-based programming: Exemplary youth development practice. New Directions for Student Leadership, 2011(130), 105-119. doi:10.1002/yd.400

Sibthorp, J., Paisley, K., \& Gookin, J. (2007). Exploring participant development through adventure-based programming: a model from the National Outdoor Leadership School. Leisure Sciences, 29(1), 118. doi:10.1080/01490400600851346

Soga, M., \& Gaston, K. J. (2016). Extinction of experience: the loss of human-nature interactions. Frontiers in Ecology and the Environment, 14(2), 94-101. doi:10.1002/fee.12

Staples, A. F., Larson, L. R., Worsley, T. E., Green, G. T., \& Carroll, J. P. (2019). Effects of an art-based environmental education camp program on the environmental attitudes and awareness of diverse youth. The Journal of Environmental Education, 50(3), 208-222. doi:10.1080/00958964.2019.1629382

Stern, M. J., Powell, R. B., \& Ardoin, N. M. (2008). What difference does it make? Assessing outcomes from participation in a residential environmental education program. Journal of Environmental Education, 39(4), 31-43. doi:10.3200/JOEE.39.4.31-43

Strauss, A. L., \& Corbin, J. M. (1998). Basics of qualitative research: Techniques and procedures for developing grounded theory, $2^{\text {nd }}$ ed. Thousand Oaks, CA: Sage.

Thurber, C. A., Scanlin, M. M., Scheuler, L., \& Henderson, K. A. (2007). Youth development outcomes of the camp experience: evidence for multidimensional growth. Journal of Youth and Adolescence, 36, 241-254. doi:10.1007/s10964-006-9142-6

Ungar, M., Dumond, C., \& McDonald, W. (2005). Risk, resilience and outdoor programmes for at-risk children. Journal of Social Work, 5(3), 319-338. doi:10.1177/1468017305058938 
Journal of Youth Development | http://jyd.pitt.edu/ | Vol. 14 Issue 4 DOI 10.5195/jyd.2019.809

\section{Urban Youth and Outdoor Adventure Camp}

Vandell, D. L. (2013). Afterschool program quality and student outcomes: Reflections on positive key findings on learning and development from recent research. In T.K. Peterson's (Ed.), Expanding Minds and Opportunities (pp. 10 - 16). Washington, D.C.: Collaborative Communications Group.

Warren, K., Roberts, N. S., Breunig, M., \& Alvarez, M. A. G. (2014). Social justice in outdoor experiential education: A state of knowledge review. Journal of Experiential Education, 37, 1-15. doi:10.1177/1053825913518898

White, E. M., Bowker, J. M., Askew, A. E., Langner, L. L., Arnold, J. R., \& English, D. B. K. (2016). Federal outdoor recreation trends: Effects on economic opportunities. Retrieved from https://www.fs.fed.us/pnw/pubs/pnw_gtr945.pdf 